\title{
Matrix-producing Carcinoma as an Aggressive Triple-negative Breast Cancer: Clinicopathological Features and Response to Neoadjuvant Chemotherapy
}

\author{
KAZUHIRO SHIMADA ${ }^{1,2}$, TAKASHI ISHIKAWA ${ }^{3}$, AKIMITSU YAMADA ${ }^{4}$, SADATOSHI SUGAE $^{4}$, \\ KAZUTAKA NARUI ${ }^{1}$, DAISUKE SHIMIZU ${ }^{5}$, TAKASHI CHISHIMA ${ }^{6}$ and ITARU ENDO ${ }^{4}$ \\ ${ }^{1}$ Department of Breast and Thyroid Surgery, Yokohama City University Medical Centre, Yokohama, Japan; \\ ${ }^{2}$ Department of Breast Surgery, Chigasaki Municipal Hospital, Chigasaki, Japan; \\ ${ }^{3}$ Department of Breast Surgery and Oncology, Tokyo Medical University, Tokyo, Japan; \\ ${ }^{4}$ Department of Gastrointestinal Surgery, Yokohama City University Graduate School of Medicine, Yokohama, Japan; \\ ${ }^{5}$ Breast Centre, Yokohama City Minato Red Cross Hospital, Yokohama, Japan; \\ ${ }^{6}$ Department of Breast Surgery, Yokohama Rosai Hospital, Yokohama, Japan
}

\begin{abstract}
Background: Breast matrix-producing carcinomas (MPCs) are rare, and usually triple-negative (TNBC; i.e. oestrogen receptor-, progesterone receptor-, and human epidermal growth factor receptor 2-negative). This study evaluated the clinical features, immunohistochemical profiles, and pathological response to neoadjuvant chemotherapy (NAC) of patients with MPCs. Patients and Methods: Five MPCs were identified among 247 patients with TNBC receiving anthracycline- and taxane-based NAC. Pathological response was assessed using surgical specimens. Results: All tumours were histological grade 3 according to pre-treatment core biopsies. Mean Ki-67 and p53 positivity were $65 \%$ and $90 \%$, respectively. All tumours were TNBC, and epidermal growth factor receptor-, cytokeratin 5/6-, and vimentinpositive. Grade 3 (pathological complete response) was achieved in $0 \%(0 / 5)$ and $32 \%$ (77/242) of those with MPCs and with TNBCs of no specific histological type, respectively, and grade 1a (poor response) in 80\% (4/5) and 13\% (31/242), respectively. Conclusion: MPCs are basal-type TNBCs expressing epithelial-mesenchymal transition markers, with a poor response to standard NAC. Further studies are needed to improve the treatment of this rare but aggressive tumour. Matrix-producing carcinoma (MPC) of the breast is a rare and specialized histological type of metaplastic carcinoma (1). MPC is defined as an invasive breast carcinoma with
\end{abstract}

Correspondence to: Kazuhiro Shimada, MD, Ph.D., Department of Breast and Thyroid Surgery, Yokohama City University Medical Centre, 4-57 Urafunecho, Minami-ku, Yokohama 232-0024, Japan. Tel: +81 452615656, Fax: +81 452535736, e-mail: kazu90052003@yahoo.co.jp

Key Words: Breast cancer, matrix-producing carcinoma, triplenegative, neoadjuvant chemotherapy, basal subtype. direct transition to a cartilaginous or osseous matrix with no intervening spindle-cell component. MPCs resemble triplenegative breast cancer (TNBC), defined as oestrogen receptor (ER)-, progesterone receptor (PR)-, and human epidermal growth factor receptor 2 (HER2)-negative (2-4). This tumour should, thus be, initially treated with chemotherapy. Although effective standardized regimens have been established for TNBC of no special histological type (NST TNBC), the efficacy of these treatments for minor histological types are unknown because of their rareness. We report five MPCs treated with neoadjuvant chemotherapy (NAC) followed by surgery, and evaluate the clinical features, immunohistochemical expression profiles, and pathological response to NAC compared with NST TNBC.

\section{Patients and Methods}

Patients and treatment. Five cases of MPC were identified among 247 patients with TNBC who received NAC at Yokohama City University Medical Centre (Yokohama, Japan) between 2007 and 2015. Prior to surgery, patients received NAC consisting of sequential chemotherapy with FEC (fluorouracil $500 \mathrm{mg} / \mathrm{m}^{2}$, epirubicin $100 \mathrm{mg} / \mathrm{m}^{2}$, cyclophosphamide $500 \mathrm{mg} / \mathrm{m}^{2}, q 3 w$ ) or EC (epirubicin $100 \mathrm{mg} / \mathrm{m}^{2}$, cyclophosphamide $500 \mathrm{mg} / \mathrm{m}^{2}, q 3 w$ ) and docetaxel $\left(75 \mathrm{mg} / \mathrm{m}^{2}, q 3 w\right)$. One patient diagnosed with a T4 tumour received sequential EC, docetaxel, and TC (docetaxel $75 \mathrm{mg} / \mathrm{m}^{2}$, cyclophosphamide $\left.600 \mathrm{mg} / \mathrm{m}^{2}, q 3 w\right)$. All patients with stage II or III TNBC breast cancer were eligible for NAC. Patients with stage IV TNBC were eligible if NAC followed by surgery was needed for local control. All patients were staged according to the World Health Organization (WHO) classification (5).

Tissue preparation and immunohistochemistry. Core needle biopsy specimens from patient's pre-chemotherapy were fixed in $20 \%$ $(\mathrm{w} / \mathrm{v})$ phosphate-buffered formalin and embedded in paraffin. Hematoxylin and eosin-stained sections were prepared using routine histological techniques and graded according to the WHO 
Table I. Antibodies used in this study. Antigen retrieval was achieved by autoclaving tissue sections in 0.1 mmol/l citrate buffer, pH 6.0 for 40 min at $95^{\circ} \mathrm{C}$.

\begin{tabular}{lccc}
\hline Antigen & Antibody type & Clone & Source \\
\hline Ki-67 & Monoclonal & MIB-1 & Dako, Glostrup, Denmark \\
ER & Monoclonal & SP1 & Roche Diagnostics, Basel, Switzerland \\
PR & Monoclonal & $1 \mathrm{E} 2$ & Roche Diagnostics \\
HER2 & Polyclonal & DO-7 & Dako, Glostrup, Denmark \\
p53 & Monoclonal & 3 C6 & Dako, Glostrup, Denmark \\
EGFR & Monoclonal & D5/16 B4 & Roche Diagnostics, Basel, Switzerland \\
CK5/6 & Monoclonal & V9 & Dako, Glostrup, Denmark \\
Vimentin & Monoclonal & ALDH1A1 & Dako, Glostrup, Denmark \\
ALDH1 & Monoclonal & Abcam, Cambridge, England \\
\hline
\end{tabular}

ER: Oestrogen receptor; PR: progesterone receptor; HER2: human epidermal growth factor receptor 2; EGFR: human epidermal growth factor receptor; CK: cytokeratin; ALDH1: aldehyde dehydrogenase 1.

classification (5). Immunohistochemical staining was performed using a Dako-Autostainer (Dako, Kyoto, Japan), with the primary antibodies listed in Table I. Positive cytokeratin (CK)5/6 and epidermal growth factor receptor (EGFR) expression were indicated by weak or strong carcinoma cell staining in the cytoplasm and membrane. Tumours staining positively for CK5/6 or EGFR were considered as basal subtype, while double-negatively stained tumours were defined as non-basal (6). Aldehyde dehydrogenase 1 (ALDH1) expression was classified as positive when $>1 \%$ of tumour cells showed clear cytoplasmic staining (7-9).

Evaluation of pathological response. Slides were assessed by two pathologists at our Institution in a blinded manner. Pathological response to chemotherapy was assessed using the grading system (grades 3, 2b, 2a, 1b, 1a, and 0) according to Japanese Breast Cancer Society criteria (10). The grades were defined as follows: Grade 3: necrosis or disappearance of all invasive tumour cells (i.e. pathological complete response; pCR) (11); grade 2b: marked disappearance of invasive cancer cells and only focal residual clusters detected; grade $2 \mathrm{a}$ : marked change in $\geq 66 \%$ of cancer cells; grade $1 \mathrm{~b}$ : marked change in $\geq 33 \%$ but $<66 \%$ of cancer cells; grade 1a: change in cancer cells regardless of the area, or marked changes in $<33 \%$ of cancer cells; and grade 0 : almost no change in cancer cells after treatment. Grades 0 and $1 \mathrm{a}$ were considered extremely poor pathological responses.

\section{Results}

The clinicopathological features and treatments of the five patients with MPC are summarized in Table II. All patients were women (mean age $=53$ years). The average tumour size was $5.5 \mathrm{~cm}$. Magnetic resonance imaging (MRI) or computed tomography (CT) showed an enhanced ring-like appearance (Figure 1). Three patients $(60 \%)$ had positive axillary lymph nodes. The mean $\mathrm{Ki}-67$ and $\mathrm{p} 53$ positivity was $65 \%$ and $90 \%$, respectively. All tumours were TNBCs which were positive for EGFR or CK5/6, and for the epithelial-mesenchymal transition (EMT) marker vimentin $(12,13)$. All tumours were negative for the breast cancer stem cell marker ALDH1 (9, 14). Representative immunohistochemical images are shown in Figure 2. All patients were treated with NAC followed by surgery, and the percentages of each pathological response grade in the MPC and NST TNBC cases are shown in Figure 3. No patients with MPC achieved pCR (grade 3), and 60\% (3/5) of patients showed an extremely poor tumour response (grade 1a), compared with only $13 \%$ (31/242) of patients with NST TNBC. Regarding the prognosis of patients with MPC after NAC and surgery, three $(60 \%)$ died of metastatic disease within 4 years and two (40\%) with small or node-negative tumours remained alive after 5 years.

\section{Discussion}

MPC is a rare tumour with few reported studies, which included a small number of cases (15). We only identified five MPC cases (2.0\%) among 247 patients with TNBC treated with NAC between 2007 and 2015. The prevalence of MPC cases among all patients with operable breast cancer was only $0.3 \%$ at our Institution. Kusafuka et al. and Okuyama et al. reported prevalence of MPCs among all invasive breast cancer cases of $0.2 \%$ and $0.05 \%$, respectively $(16,17)$. Given that metaplastic carcinomas are rare, MPCs comprise $<1 \%$ of all invasive breast carcinomas. DownsKelly et al. reported 32 cases of MPC (2), all of whom were female (mean age 50 years), similarly to the current cases. However, they reported a median primary tumour size of 3.0 $\mathrm{cm}$ compared with $5.5 \mathrm{~cm}$ in our study. The median tumour size for 1,325 patients with NST TNBC treated at our Institution between 1997 and 2015 was $2.0 \mathrm{~cm}$, indicating that MPCs tend to be larger than NST TNBCs.

Some radiological findings of MPCs have been reported (16). Imaging diagnosis using contrast-enhanced CT or MRI revealed irregularly shaped tumours with peripheral ringshaped contrast enhancement, as in the current cases. This 
Table II. Clinicopathological features and treatment response of patients with matrix-producing carcinoma.

\begin{tabular}{|c|c|c|c|c|c|}
\hline & Case 1 & Case 2 & Case 3 & Case 4 & Case 5 \\
\hline Age (years) & 53 & 65 & 50 & 43 & 57 \\
\hline Tumor size $(\mathrm{cm})$ & $8.6 \times 6.0 \times 5.0$ & $3.2 \times 2.7 \times 2.5$ & $1.5 \times 1.3 \times 1.0$ & $3.7 \times 3.5 \times 3.5$ & $10 \times 10 \times 5.0$ \\
\hline Site & Lt EBD & Rt BDE & Lt C & Rt C & Lt ABCDE \\
\hline Lymph node status & + & + & - & - & + \\
\hline Clinical stage & $\mathrm{T} 3 \mathrm{~N} 1 \mathrm{M} 0$ & $\mathrm{~T} 2 \mathrm{~N} 2 \mathrm{M} 0$ & T2N0M0 & T2N0M0 & T4N2M1 \\
\hline Histological grade & 3 & 3 & 3 & 3 & 3 \\
\hline Ki-67 (\%) & 69 & 74 & 65 & 50 & 45 \\
\hline p53 (\%) & 81 & 100 & 100 & 90 & 90 \\
\hline ER & - & - & - & - & - \\
\hline PR & - & - & - & - & - \\
\hline HER2 & - & - & - & - & - \\
\hline EGFR & + & + & + & + & + \\
\hline CK5/6 & + & + & + & - & - \\
\hline Vimentin & + & + & + & + & + \\
\hline ALDH1 & - & - & - & - & - \\
\hline NAC regimen & FEC-DOC & EC-DOC & FEC-DOC & FEC-DOC & EC-DOC-TC \\
\hline Operation & $\mathrm{Bt}+\mathrm{Ax}$ & $\mathrm{Bt}+\mathrm{SNB}$ & $\mathrm{Bp}+\mathrm{SNB}$ & $\mathrm{Bt}+\mathrm{Ax}$ & $\mathrm{Bt}+\mathrm{Ax}$ \\
\hline Pathological response & 1a & $1 \mathrm{a}$ & $2 a$ & 1a & 1a \\
\hline Follow-up (months) & $\operatorname{DOD}(46)$ & $\operatorname{DOD}(43)$ & NED (73) & NED (66) & DOD (16) \\
\hline
\end{tabular}

Site: Tumour location according to Breast Cancer ICD-10 Code; Lt: left; Rt: right; A: upper-inner quadrant; B: lower-inner quadrant; C: upper-outer quadrant; D: lower-outer quadrant; E: central portion; -: negative for marker; +: positive for marker; ER: oestrogen receptor; PR: progesterone receptor; HER2: human epidermal growth factor receptor 2; EGFR: epidermal growth factor receptor; CK5/6: cytokeratin 5/6; ALDH1: aldehyde dehydrogenase 1; NAC: neoadjuvant chemotherapy; FEC: $500 \mathrm{mg} / \mathrm{m}^{2}$ fluorouracil, $100 \mathrm{mg} / \mathrm{m}^{2}$ epirubicin, $500 \mathrm{mg} / \mathrm{m}^{2}$ cyclophosphamide; DOC: $75 \mathrm{mg} / \mathrm{m}^{2} \mathrm{docetaxel}$; EC: $100 \mathrm{mg} / \mathrm{m}^{2}$ epirubicin, $500 \mathrm{mg} / \mathrm{m}^{2}$ cyclophosphamide; TC: $75 \mathrm{mg} / \mathrm{m}^{2}$ docetaxel, $600 \mathrm{mg} / \mathrm{m}^{2}$ cyclophosphamide; Bt: total mastectomy; Bp: partial mastectomy; Ax: axillary lymph node dissection; SNB: sentinel node biopsy; DOD: died of disease; NED: no evidence of disease.

was likely caused by a ring of carcinoma cells at the tumour periphery and a matrix component in the centre of the tumour. We therefore considered the possibility of an MPC diagnosis when such images were obtained. The current study found a high rate $(60 \%)$ of axillary lymph node metastasis at diagnosis; conversely, Downs-Kelly et al. and Shui et al. showed lower rates of $22 \%$ and $7.7 \%$, respectively $(2,4)$. Further analyses of large numbers of age/tumour grade-matched patients with NST TNBC are needed.

Most metaplastic breast carcinomas are TNBCs $(1,2,18)$, including all MPCs of the current study; it is notable that no cases of MPC were detected in any of our patients with nonTNBC. Furthermore, all the MPCs demonstrated high proliferative activity, indicated by high histological grade, high Ki-67 index, and high level of p53 expression. The mean Ki-67 index of the MPCs $(45 \%)$ was higher than that of NST TNBCs (36\%), suggesting that MPCs are a biologically aggressive subgroup of TNBC. Notably, all MPCs in this study expressed EGFR, in $3 / 5$ cases concomitantly with CK5/6, which are markers of basal subtype. Few studies have examined the relationship between basal subtype and MPCs. Shui et al. reported that eight out of 10 patients with MPC were positive for CK5/6 or EGFR (4). These results suggest that MPC should clinically be regarded as a basal subtype of TNBC.
In regard to EMT and mutation of breast cancer susceptibility gene 1 (BRCA1), the basal subtype was recently shown to largely overlap with TNBC $(12,19)$. EMT is associated with increased aggressiveness and invasive and metastatic potential of breast cancer, and is characterized by up-regulation of the key EMT marker, vimentin $(12,20)$. Okuyama et al. found that specimens from eight patients with MPC were all positive for vimentin, as in our cases (17). Furthermore, vimentin has been reported to be a poor prognostic factor, especially in TNBC (13). All MPCs in the present study were basal subtype TNBC with positive vimentin expression.

MPCs are thought to be part of the TNBC spectrum, and to be biologically aggressive with an EMT-like molecular make-up. Genetically, the claudin-low subtype is characterized by enrichment of EMT markers, and largely overlaps with the genetic features of metaplastic breast cancer $(21,22)$. MPCs may thus be regulated similarly to claudin-low subtype breast cancer. This perspective may further our understanding of the biological features of MPCs and thus aid the development of novel anticancer-targeted therapies for this rare tumour type.

BRCA1 mutations cause hereditary breast cancer and have been associated with up to $15 \%$ of TNBCs, while TNBCs in turn account for $70 \%$ of breast tumours arising in $B R C A 1$ mutation carriers (23). TNBC with BRCAl mutation is 


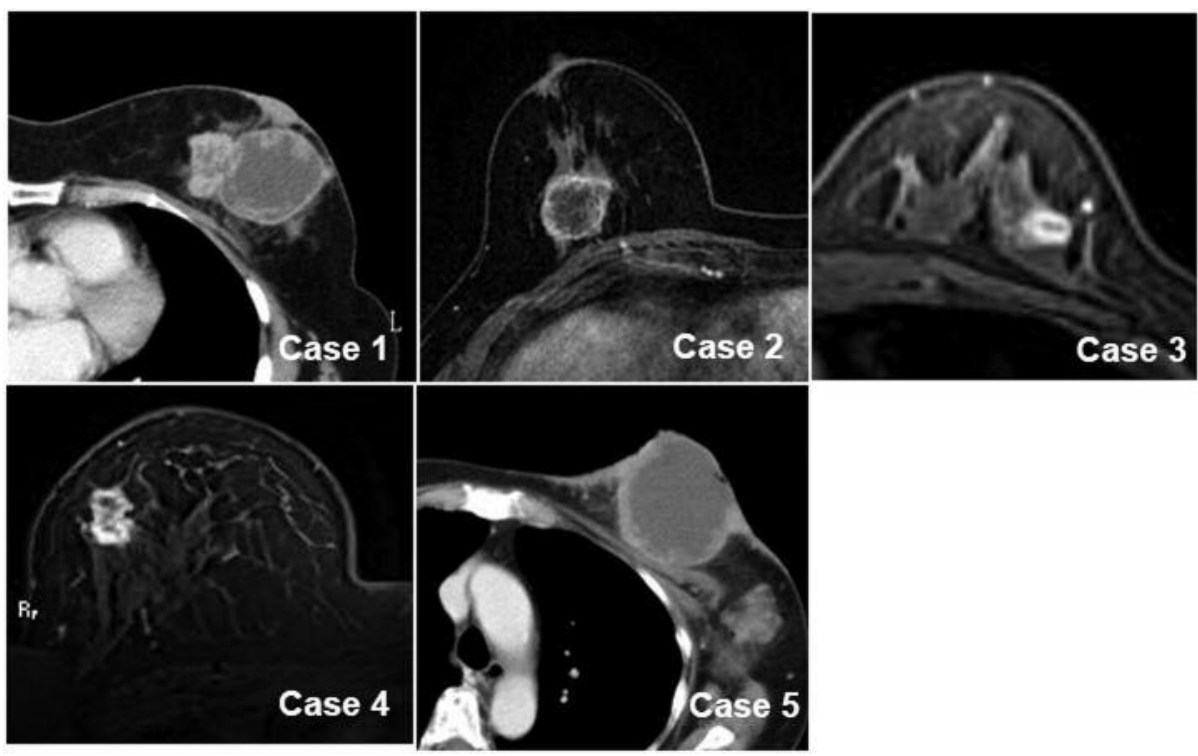

Figure 1. Primary matrix-producing carcinoma. Peripheral ring-shaped contrast enhancement is apparent in all cases. Cases 1 and 5, enhanced computed tomography; Cases 2-4, T1-weighted enhanced magnetic resonance imaging.

strongly associated with basal subtype TNBC, mostly showing higher histological grade, higher Ki-67 index, and more $p 53$ mutations, compared with tumours from agematched patients with sporadic breast cancer $(19,24)$. These characteristics were compatible with those of the current MPC cases, although none of these had any particular family history of breast cancer, and their BRCAl status was not investigated. Further studies are needed to clarify the relationship between MPCs and BRCAl mutations.

MPC is a rare disease with little published information to guide therapeutic choices. MPCs are negative for ER, PR, and HER2, and thus no targeted therapies are currently available, making conventional chemotherapy the backbone of systemic treatment for MPCs as well as for NST TNBC. NAC is associated with high pathological response rates in NST TNBC, but metaplastic carcinomas are usually chemoresistant $(25,26)$. However, information required to evaluate the impact of NAC on pathological response of MPCs is currently lacking. No patients in this study achieved a grade 3 (pCR) response to NAC, and most patients with MPC showed poor pathological responses (assessed as grade 1a tumours) compared with those with NST TNBC. Dosedense perioperative chemotherapy (DDCT) has recently been used in a clinical setting to improve the prognosis of patients with high-risk TNBC (27), and DDCT may thus be a possible effective treatment option for MPC.

Recent studies showed that chemoresistance in metaplastic carcinomas, potentially claudin-low or basal subtype tumours, might stem from their EMT-like molecular make-up, down- regulation of DNA damage response pathways $(22,28)$, and enrichment of stem cell-like markers. Patients with TNBC with poor pathological responses to NAC have poorer clinical outcomes, and new treatments for MPC should thus be based on their specific expression profiles. The recently refined version of the TNBC molecular classification defined four main subtypes: Basal 1, basal 2, mesenchymal, and luminal androgen receptor subtypes, with unique ontologies and differential responses to therapy (29). They reported that basal 2 subtype, characterized by the expression of EGFR and TP63 similarly to the MPCs in the current study, responded to antimitotic agents such as platinum salts and poly ADP ribose polymerase (PARP) inhibitors. PARP inhibitors have been used to treat basal subtype breast tumours (30), especially poorly differentiated tumours with EMT features and defects in homologous recombination DNA repair (31). Furthermore, a recent large study showed that PARP inhibitors provided significant benefits over standard therapy in patients with metastatic TNBC and BRCAl/2 mutation (32). These new agents might be promising targeted treatments for MPC. Regarding chemoresistance and the association with stem celllike markers, the relationship between MPCs and ALDH1 remains unclear. Few published studies have reported on the expression of cancer stem cell markers in specific histological types of breast cancer, and in contrast to our results, these studies showed enrichment of markers such as ALDH1 in metaplastic breast carcinomas, including MPCs (14, 33). Further translational and clinical studies with large numbers of cases are therefore needed. 


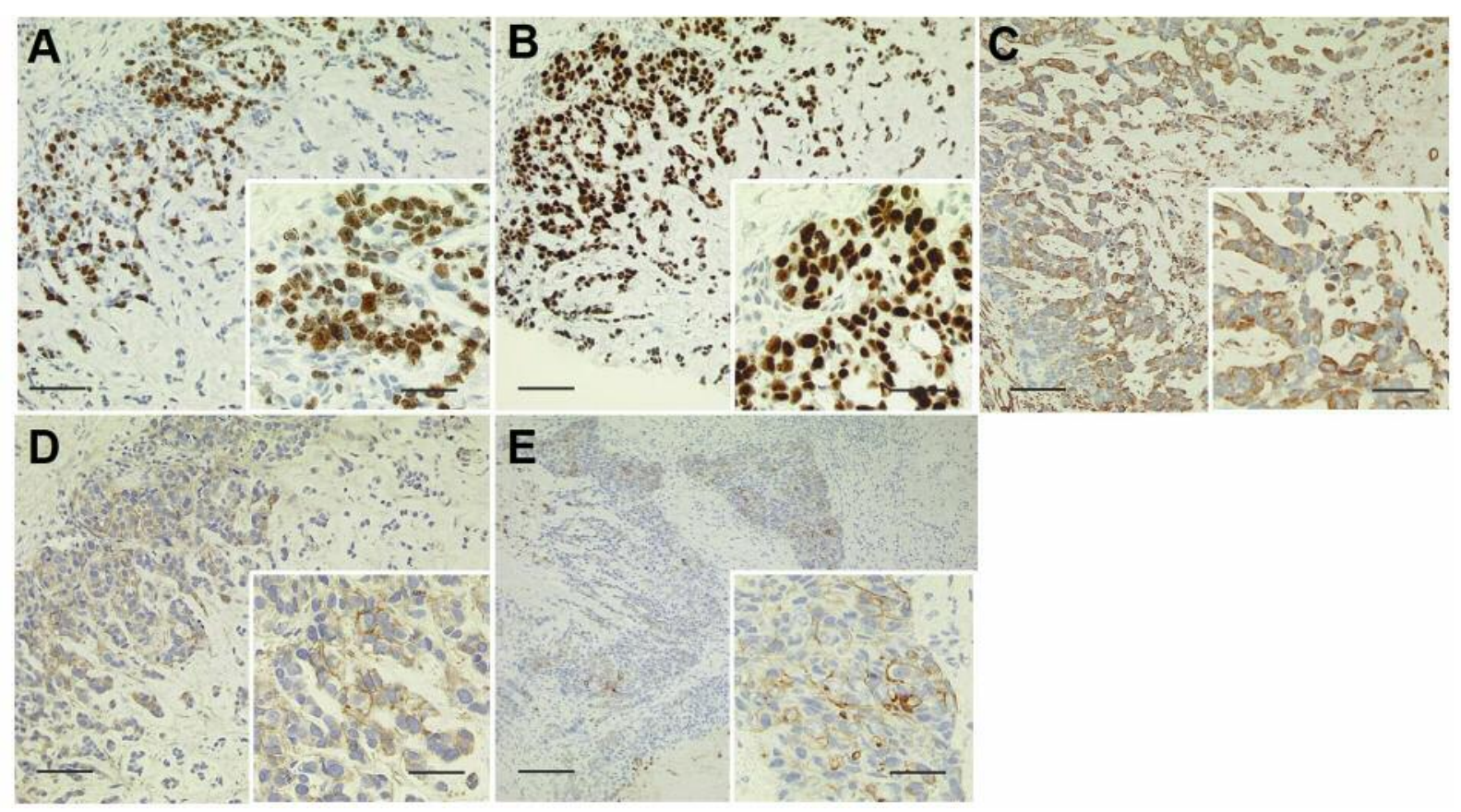

Figure 2. Representative immunohistochemical images. A: Positivity for Ki-67 was observed in $75 \%$ of tumour cell nuclei. B: Positive p53 staining was observed in $100 \%$ of tumour cell nuclei. C: Positive vimentin staining was observed in the cytoplasm of cancer cells, but not in the matrix component. D: Positive epidermal growth factor receptor staining was observed in the cytoplasm/membrane of carcinoma cells. E: Cytokeratin 5/6 staining was observed in the cytoplasm/membrane of carcinoma cells. Scale bars, $50 \mu \mathrm{m}$; inset, $25 \mu \mathrm{m}$.

MPC is an extremely rare disease. Patients with MPC present with TNBC, larger tumour size, higher lymph node involvement, higher grade, $p 53$ mutations, a higher Ki-67 index, and frequent expression of vimentin and basal markers. They also show a markedly poor pathological response to conventional NAC regimens compared to patients with NST TNBC, suggesting that MPCs comprise a novel chemoresistant subgroup of TNBC. Based on the unique biological features of MPCs, new chemotherapeutic regimens including agents such as DDCT, platinum salts, and PARP inhibitors may be required to treat this rare, but aggressive subtype of TNBC.

\section{Conflicts of Interest}

The Authors declare that they have no conflicts of interest in regard to this study.

\section{Authors' Contributions}

Conception and design: KS; Acquisition of data: KS, AY, DS; Analysis and interpretation of data: KS, TI; Drafting the article: KS; Critically revising the article for important intellectual content: TI, SS, KN, TC; Final approval of the version to be published: IE; All Authors read and approved the final article.

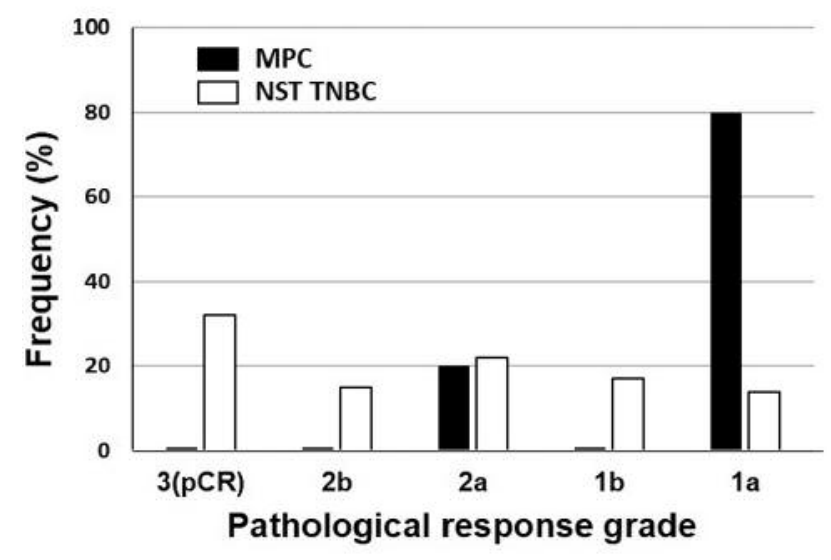

Figure 3. Distribution of pathological response grades in patients with matrix-producing carcinoma (MPC) and with triple-negative breast cancer of no special histological type (NST TNBC) treated with neoadjuvant chemotherapy at our Institution.

\section{Acknowledgements}

The Authors thank Susan Furness, PhD, from Edanz Group (www.edanzediting.com/ac) for editing a draft of this article. 


\section{References}

1 Wargotz ES and Norris HJ: Metaplastic carcinomas of the breast. I. Matrix-producing carcinoma. Hum Pathol 20: 628-635, 1989. PMID: 2544506.

2 Downs-Kelly E, Nayeemuddin KM, Albarracin C, Wu Y, Hunt KK and Gilcrease MZ: Matrix-producing carcinoma of the breast: an aggressive subtype of metaplastic carcinoma. Am J Surg Pathol 33: 534-541, 2009. PMID: 19047898. DOI: 10.1097/PAS.0b013e31818ab26e

3 Rakha EA, Tan PH, Shaaban A, Tse GM, Esteller FC, van Deurzen CH, Purnell D, Stotter A, Chan T, Yamaguchi R, Dodwell D, Jager A, Soler MT, Juneinah E, Plaza ML, Hodi Z, McCulloch T, Lee AH and Ellis IO: Do primary mammary osteosarcoma and chondrosarcoma exist? A review of a large multi-institutional series of malignant matrix-producing breast tumours. Breast 22: 13-18, 2013. PMID: 23084962. DOI: 10.1016/j.breast.2012.09.010

4 Shui R, Bi R, Cheng Y, Lu H, Wang J and Yang W: Matrixproducing carcinoma of the breast in the Chinese population: A clinicopathological study of 13 cases. Pathol Int 61: 415-422, 2011. PMID: 21707845. DOI: 10.1111/j.1440-1827.2011.02 676.x

5 Sunil L, Ian E, Stuart S and Puay T: WHO Classification of Tumours of the Breast. World Health Organization. Fourth Edition. 2012. ISBN: 9789283224334.

6 Nielsen TO, Hsu FD, Jensen K, Cheang M, Karaca G, Hu Z, Hernandez-Boussard T, Livasy C, Cowan D, Dressler L, Akslen LA, Ragaz J, Gown AM, Gilks CB, van de Rijn M and Perou $\mathrm{CM}$ : Immunohistochemical and clinical characterization of the basal-like subtype of invasive breast carcinoma. Clin Cancer Res 10: 5367-5374, 2004. PMID: 15328174. DOI: 10.1158/10780432.CCR-04-0220

7 Ricardo S, Vieira AF, Gerhard R, Leitão D, Pinto R, CameselleTeijeiro JF, Milanezi F, Schmitt F and Paredes J: Breast cancer stem cell markers CD44, CD24 and ALDH1: Expression distribution within intrinsic molecular subtype. J Clin Pathol 64: 937-946, 2011. PMID: 21680574. DOI: 10.1136/jcp.2011. 090456

8 Deng S, Yang X, Lassus H, Liang S, Kaur S, Ye Q, Li C, Wang LP, Roby KF, Orsulic S, Connolly DC, Zhang Y, Montone K, Bützow R, Coukos G and Zhang L: Distinct expression levels and patterns of stem cell marker, aldehyde dehydrogenase isoform 1 (ALDH1), in human epithelial cancers. PLoS One 5: e10277, 2010. PMID: 20422001. DOI: 10.1371/journal.pone. 0010277

9 Ginestier C, Hur MH, Charafe-Jauffret E, Monville F, Dutcher J, Brown M, Jacquemier J, Viens P, Kleer CG, Liu S, Schott A, Hayes D, Birnbaum D, Wicha MS and Dontu G: ALDH1 is a marker of normal and malignant human mammary stem cells and a predictor of poor clinical outcome. Cell Stem Cell 1: 555567, 2007. PMID: 18371393. DOI: 10.1016/j.stem.2007.08.014

10 Society JBC: General Rules for Clinical and Pathological Recording of Breast Cancer. 18th Edition. Tokyo: Kanahara Shuppan, 2018.

11 Mazouni C, Peintinger F, Wan-Kau S, Andre F, GonzalezAngulo AM, Symmans WF, Meric-Bernstam F, Valero V, Hortobagyi GN and Pusztai L: Residual ductal carcinoma in situ in patients with complete eradication of invasive breast cancer after neoadjuvant chemotherapy does not adversely affect patient outcome. J Clin Oncol 25: 2650-2655, 2007. PMID: 17602071. DOI: $10.1200 / \mathrm{JCO} .2006 .08 .2271$
12 Sarrio D, Rodriguez-Pinilla SM, Hardisson D, Cano A, MorenoBueno $G$ and Palacios J: Epithelial-mesenchymal transition in breast cancer relates to the basal-like phenotype. Cancer Res 68 : 989-997, 2008. PMID: 18281472. DOI: 10.1158/0008-5472. CAN-07-2017

13 Yamashita N, Tokunaga E, Kitao H, Hisamatsu Y, Taketani K, Akiyoshi S, Okada S, Aishima S, Morita M and Maehara Y: Vimentin as a poor prognostic factor for triple-negative breast cancer. J Cancer Res Clin Oncol 139: 739-746, 2013. PMID: 23354842. DOI: $10.1007 / \mathrm{s} 00432-013-1376-6$

14 de Beca FF, Caetano P, Gerhard R, Alvarenga CA, Gomes M, Paredes J and Schmitt F: Cancer stem cells markers CD44, CD24 and ALDH1 in breast cancer special histological types. J Clin Pathol 66: 187-191, 2013. PMID: 23112116. DOI: 10.1136/jclinpath-2012-201169

15 Ayar S, Dyess DL and Carter E: Matrix-producing carcinoma: A rare variant of metaplastic breast carcinoma with heterologous elements. Breast J 16: 420-423, 2010. PMID: 20522099. DOI: 10.1111/j.1524-4741.2010.00925.x

16 Kusafuka K, Muramatsu K, Kasami M, Kuriki K, Hirobe K, Hayashi I, Watanabe H, Hiraki Y, Shukunami C, Mochizuki T and Kameya T: Cartilaginous features in matrix-producing carcinoma of the breast: Four cases report with histochemical and immunohistochemical analysis of matrix molecules. Mod Pathol 21: 1282-1292, 2008. PMID: 18622387. DOI: 10.1038/ modpathol.2008.120

17 Okuyama N, Sakamoto G, Sakai T, Tokutome N, Sarumaru S, Hori F, Horii R, Akiyama F and Kasumi F: Clinicopathological features of matrix-producing carcinoma. Jpn J Breast Cancer 19: 339-342, 2004. ISSN: 0911-2251.

18 Gibson GR, Qian D, Ku JK and Lai LL: Metaplastic breast cancer: Clinical features and outcomes. Am Surg 71: 725-730, 2005. PMID: 16468506.

19 Lavasani MA and Moinfar F: Molecular classification of breast carcinomas with particular emphasis on "basal-like" carcinoma: A critical review. J Biophotonics 5: 345-366, 2012. PMID: 22232077. DOI: $10.1002 /$ jbio.201100097

20 Kokkinos MI, Wafai R, Wong MK, Newgreen DF, Thompson EW and Waltham M: Vimentin and epithelial-mesenchymal transition in human breast cancer - observations in vitro and in vivo. Cells Tissues Organs 185: 191-203, 2007. PMID: 17587825. DOI: $10.1159 / 000101320$

21 Gerhard R, Ricardo S, Albergaria A, Gomes M, Silva AR, Logullo ÂF, Cameselle-Teijeiro JF, Paredes J and Schmitt F: Immunohistochemical features of claudin-low intrinsic subtype in metaplastic breast carcinomas. Breast 21: 354-360, 2012. PMID: 22464177. DOI: 10.1016/j.breast.2012.03.001

22 Hennessy BT, Gonzalez-Angulo AM, Stemke-Hale K, Gilcrease MZ, Krishnamurthy S, Lee JS, Fridlyand J, Sahin A, Agarwal R, Joy C, Liu W, Stivers D, Baggerly K, Carey M, Lluch A, Monteagudo C, He X, Weigman V, Fan C, Palazzo J, Hortobagyi GN, Nolden LK, Wang NJ, Valero V, Gray JW, Perou CM and Mills GB: Characterization of a naturally occurring breast cancer subset enriched in epithelial-tomesenchymal transition and stem cell characteristics. Cancer Res 69: 4116-4124, 2009. PMID: 19435916. DOI: 10.1158/0008-5472.CAN-08-3441

23 Stevens KN, Vachon CM and Couch FJ: Genetic susceptibility to triple-negative breast cancer. Cancer Res 73: 2025-2030, 2013. PMID: 23536562. DOI: 10.1158/0008-5472.CAN-12-1699 
24 Lakhani SR, Reis-Filho JS, Fulford L, Penault-Llorca F, van der Vijver M, Parry S, Bishop T, Benitez J, Rivas C, Bignon YJ, Chang-Claude J, Hamann U, Cornelisse CJ, Devilee P, Beckmann MW, Nestle-Krämling C, Daly PA, Haites N, Varley J, Lalloo F, Evans G, Maugard C, Meijers-Heijboer H, Klijn JG, Olah E, Gusterson BA, Pilotti S, Radice P, Scherneck S, Sobol H, Jacquemier J, Wagner T, Peto J, Stratton MR, McGuffog L, Easton DF and Breast Cancer Linkage Consortium: Prediction of BRCA1 status in patients with breast cancer using estrogen receptor and basal phenotype. Clin Cancer Res 11: 5175-5180, 2005. PMID: 16033833. DOI: 10.1158/1078-0432.CCR-04-2424

25 Al Sayed AD, El Weshi AN, Tulbah AM, Rahal MM and Ezzat AA: Metaplastic carcinoma of the breast clinical presentation, treatment results and prognostic factors. Acta Oncol 45: 188195, 2006. PMID: 16546865. DOI: 10.1080/02841 860500 513235

26 Hennessy BT, Giordano S, Broglio K, Duan Z, Trent J, Buchholz TA, Babiera G, Hortobagyi GN and Valero V: Biphasic metaplastic sarcomatoid carcinoma of the breast. Ann Oncol 17: 605-613, 2006. PMID: 16469754. DOI: 10.1093/annonc/mdl006

27 Lambertini M, Ceppi M, Cognetti F, Cavazzini G, De Laurentiis M, De Placido S, Michelotti A, Bisagni G, Durando A, Valle E, Scotto T, De Censi A, Turletti A, Benasso M, Barni S, Montemurro F, Puglisi F, Levaggi A, Giraudi S, Bighin C, Bruzzi P, Del Mastro L and MIG and GIM study groups: Dosedense adjuvant chemotherapy in premenopausal breast cancer patients: A pooled analysis of the MIG1 and GIM2 phase III studies. Eur J Cancer 71: 34-42, 2017. PMID: 27951450. DOI: 10.1016/j.ejca.2016.10.030

28 Weigelt B, Kreike B and Reis-Filho JS: Metaplastic breast carcinomas are basal-like breast cancers: A genomic profiling analysis. Breast Cancer Res Treat 117: 273-280, 2009. PMID: 18815879. DOI: 10.1007/s10549-008-0197-9
29 Lehman BD, Jovanović B, Chen X, Estrada MV, Johnson KN, Shyr Y, Moses HL, Sanders ME and Pietenpol JA: Refinement of triple-negative breast cancer molecular subtypes: Implications for neoadjuvant chemotherapy selection. PLoS One 11: e0157368, 2016. PMID: 27310713. DOI: 10.1371/journal.pone. 0157368

30 Gerratana L, Basile D, Buono G, De Placido S, Giuliano M, Minichillo S, Coinu A, Martorana F, De Santo I, Del Mastro L, De Laurentiis M, Puglisi F and Arpino G: Androgen receptor in triple-negative breast cancer: A potential target for the targetless subtype. Cancer Treat Rev 68: 102-110, 2018. PMID: 29940524. DOI: $10.1016 /$ j.ctrv.2018.06.005

31 Ashworth A: A synthetic lethal therapeutic approach: Poly(ADP) ribose polymerase inhibitors for the treatment of cancers deficient in DNA double-strand break repair. J Clin Oncol 26: 3785-3790, 2008. PMID: 18591545. DOI: 10.1200/JCO.2008. 16.0812

32 Robson M, Im A-S-A, Senkus E, Xu B, Domchek SM, Masuda N, Delaloge S, Li W, Tung N, Armstrong A, Wu W, Goessl C, Runswick S and Conte P: Olaparib for metastatic breast cancer in patients with a germline BRCA mutation. N Engl J Med 377: 523-533, 2017. PMID: 28578601. DOI: 10.1056/NEJMoa170 6450

33 Zhang Y, Toy KA and Kleer CG: Metaplastic breast carcinomas are enriched in markers of tumor-initiating cells and epithelial to mesenchymal transition. Mod Pathol 25: 178-184, 2012. PMID: 22080057. DOI: 10.1038/modpathol.2011.167

Received April 22, 2019

Revised May 27, 2019

Accepted May 28, 2019 